02

\title{
Люминесценция водного раствора фотосенсибилизатора Радахлорин при возбуждении в полосах 405 и $605 \mathrm{~nm}$
}

\author{
(С) Д.М. Бельтюкова, В.П. Белик, О.С. Васютинский , И.М. Гаджиев, \\ С.Е. Гончаров, И.В. Семенова
}

Физико-технический институт им. А.Ф. Иоффре, 194021 Санкт-Петербург, Россия

ฯ e-mail: osv@pms.ioffe.ru

Поступила в редакцию 16.05.2017 г.

Получен и исследован полный спектр люминесценции водного раствора фотосенсибилизатора Радахлорин при возбуждении лазерным излучением с длиной волны $660 \mathrm{~nm}$. Обнаружен пик фосфоресценции синглетного кислорода с максимумом при $1274 \mathrm{~nm}$. Проведено сравнение полученных результатов с данными при возбуждении на длине волны $405 \mathrm{~nm}$ и показано единообразие происходящих в обоих случаях процессов релаксации и люминесценции. Для обеих длин волн возбуждения определены эффективные сечения поглощения, а также показано, что квантовый выход синглетного кислорода не зависит от концентрации фотосенсибилизатора в растворе. Определено время жизни первого триплетного состояния фотосенсибилизатора Радахлорин. Полученные результаты могут быть использованы для оптимизации методов генерации и детектирования синглетного кислорода в растворах и биологических объектах.

DOI: $10.21883 /$ OS.2018.01.45356.117-17

\section{Введение}

Для лечения онкологических заболеваний активно используется метод фотодинамической терапии [1-3], основанный на использовании генерации в тканях синглетного кислорода (СК) с помощью молекул-фотосенсибилизаторов (ФС). Сущность метода заключается в том, что ФС способны поглощать лазерное излучение и передавать полученную энергию молекулам кислорода с образованием СК [4], который взаимодействует с патологическими клетками и вызывает их гибель посредством некроза или апоптоза.

В настоящее время в медицинских целях широко используют ФС второго поколения, в том числе синтезированные на основе хлорофилла $\alpha$. Нами исследовался один из таких ФС - Радахлорин ${ }^{\circledR}$ (РадаФарма), основным компонентом которого является хлорин е 6 с добавлением пурпурина 5 и хлорина $\mathrm{p}_{6}$ [5]. Различные свойства Радахлорина исследуются уже более 10 лет [6], однако большинство этих исследований было посвящено его клиническим испытаниям [7-10]. Радахлорин имеет несколько полос поглощения, наиболее важными из которых являются полосы с максимумами на 405 и $660 \mathrm{~nm}$, положения которых незначительно изменяются в зависимости от типа растворителя, $\mathrm{pH}$ среды и концентрации ФС $[11,12]$. Наибольший коэффициент поглощения ФС соответствует длине волны возбуждения $405 \mathrm{~nm}$, однако в клинической практике используется полоса поглощения с максимумом на $660 \mathrm{~nm}$ из-за наличия окна прозрачности тканей в этой области спектра. Процессы фотовыцветания водного раствора Радахлорина исследовались в работах [13-15]. В его спектре люминесценции в видимой и ближней ИК областях имеется пик в районе $665 \mathrm{~nm}$ с крылом, быстро спадающим в сторону более длинных волн [12]. До настоящего времени спектр люминесценции Радахлорина в ИК области был мало исследован. В работе [16] был получен спектр люминесценции водного раствора этого ФС при возбуждении в полосе поглощения $405 \mathrm{~nm}$, на котором присутствует пик люминесценции СК на длине волны $1274 \mathrm{~nm}$. В работе [17] была исследована нано- и микросекундная кинетики люминесценции Радахлорина при возбуждении в полосе поглощения $405 \mathrm{~nm}$ и определены времена жизни возбужденных состояний.

В настоящей работе исследован спектр люминесценции Радахлорина в диапазоне 660-1350 nm при возбуждении лазерным излучением с длиной волны $660 \mathrm{~nm}$ и проведено сравнение с полученным ранее спектром при возбуждении на длине волны $405 \mathrm{~nm}$ [16]. В обоих случаях продемонстрирован вклад фосфоресценции СК в общий сигнал люминесценции раствора. Определены коэффициенты поглощения при возбуждении водного раствора ФС и проведено сравнение интенсивности фосфоресценции СК в зависимости от концентрации ФС при возбуждении на длинах волн 405 и $660 \mathrm{~nm}$. Получены спектральные характеристики ФС с временным разрешением при возбуждении на длине волны $660 \mathrm{~nm}$, на основе которых определено время жизни первого триплетного состояния Радахлорина.

\section{Методика эксперимента и экспериментальная установка}

Объектом исследования являлся водный раствор ФС Радахлорин ${ }^{\circledR}$, предназначенный для внутривенного введения. Перед каждой серией экспериментов приготавливался новый раствор, в качестве растворителя исполь- 


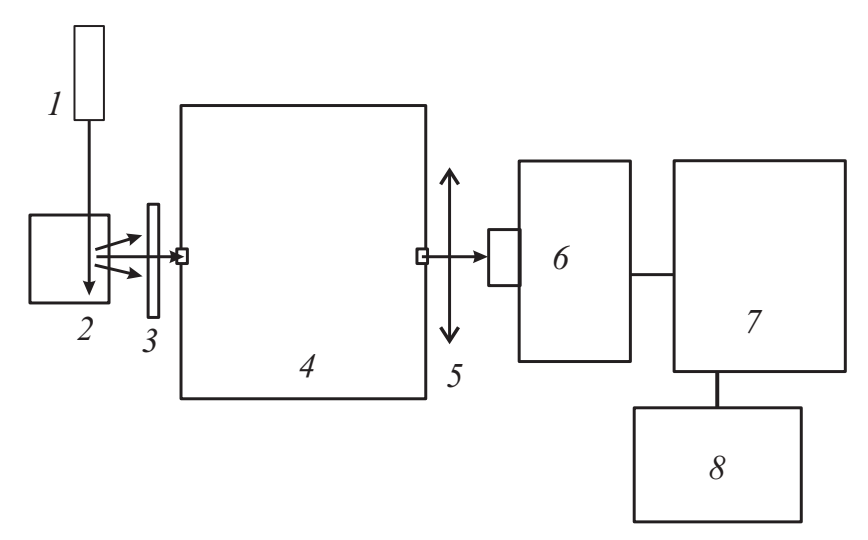

Рис. 1. Схема установки: $1-$ полупроводниковый лазер, 2 -кварцевая кювета с раствором ФС, 3 - фильтр ИКС-1, 4 - монохроматор, 5 - собирающая линза, $6-$ ФЭУ/фотодиод, 7 - счетчик фотонов/вольтметр, 8 - компьютер.

зовалась дистиллированная вода. В ходе эксперимента по регистрации спектра через каждые 10 измерений осуществлялась смена раствора во избежание фотовыцветания ФС.

Схема экспериментальной установки приведена на рис. 1. Для возбуждения использовались два полупроводниковых лазера со следующими характеристиками: (1) длина волны излучения $405 \mathrm{~nm}$ при плотности мощности $2 \mathrm{~mW} / \mathrm{mm}^{2}$, (2) длина волны излучения $660 \mathrm{~nm}$ при плотности мощности $2.7 \mathrm{~mW} / \mathrm{mm}^{2}$. Раствор ФС помещался в кварцевую кювету сечением $1 \times 1 \mathrm{~cm}^{2}$, которая устанавливалась практически вплотную к входной щели монохроматора. Возбуждение раствора производилось параллельно его поверхности вблизи стенки кюветы. В эксперименте использовался монохроматор МДР-12 с дифракционной решеткой 600 lines $/ \mathrm{mm}$ и обратной дисперсией $4.8 \mathrm{~nm} / \mathrm{mm}$, ширины входной и выходной щелей монохроматора составляли $0.5 \mathrm{~mm}$. Для устранения вклада в сигнал люминесценции рассеянного излучения лазера во втором порядке дифракции при регистрации спектра на длинах волн более $1200 \mathrm{~nm}$ использовался отсекающий фильтр ИКС-1. Регистрация интенсивности люминесценции производилась двумя фотодетекторами: в области 650-1000 nm - кремниевым фотодиодом SPD-10, а в области 940-1350 nm - инфракрасным ФЭУ NIR-PMT H10330B-45 (Hamamatsu). Сшивка полученных данных производилась в общей полосе чувствительности фотодетекторов в области 940-1000 nm. Исследование спектральных характеристик с временны́м разрешением производилось при возбуждении раствора импульсным лазером с длиной волны $660 \mathrm{~nm}$ и длительностью импульса $100 \mathrm{~ns}$ методом время-корреляционной спектроскопии в режиме счета фотонов (TCSPC) с использованием измерительного модуля PicoHarp300 (PicoQuant). При исследовании коэффициента поглощения раствора производился контроль мощности лазерного пучка, прошедшего через кювету, измерителем мощности Nova P/N 7Z01500 (Ophir).

\section{Полученные результаты и их интерпретация}

На рис. 2 представлен спектр люминесценции водного раствора Радахлорина, полученный при возбуждении в полосе поглощения $660 \mathrm{~nm}$. Для сравнения на этом же рисунке представлен спектр люминесценции, полученный при возбуждении в полосе поглощения $405 \mathrm{~nm}$ [16]. Концентрация ФС, использовавшаяся в работе [16], составляла $8.8 \cdot 10^{15} \mathrm{~cm}^{-3}$, а интенсивность возбуждающего излучения $-2 \mathrm{~mW} / \mathrm{mm}^{2}$, причем лазерное излучение было направлено сверху на поверхность раствора. В настоящем эксперименте использовался раствор Радахлорина с концентрацией $3.2 \cdot 10^{16} \mathrm{~cm}^{-3}$, а возбуждение осуществлялось излучением с интенсивностью $2.7 \mathrm{~mW} / \mathrm{mm}^{2}$ на длине волны $660 \mathrm{~nm}$. Как видно из рис. 2 , спектры люминесценции имеют в обоих случаях одинаковый характер и содержат ряд общих особенностей: плато в районе 700 и $950 \mathrm{~nm}$, а также пик фосфоресценции СК с максимумом на длине волны $1274 \mathrm{~nm}$. Различие в интенсивностях двух спектров люминесценции обусловлено разными значениями коэффициентов поглощения и мощности лазерного излучения при возбуждении в полосах 405 и $660 \mathrm{~nm}$.

Участок спектра люминесценции, содержащий пик $\mathrm{CK}$, соответствующий переходу $\mathrm{O}_{2}\left(\mathrm{a}^{1} \Delta_{\mathrm{g}}\right) \rightarrow \mathrm{O}_{2}\left(\mathrm{X}^{3} \Sigma_{\mathrm{g}}^{-}\right)$, представлен на рис. 3. Как видно из этого рисунка, относительные вклады фосфоресценции СК в общий сигнал в обоих случаях совпадали в пределах погрешности измерений.

Полученные результаты свидетельствуют о том, что процессы безызлучательной релаксации после возбуждения в каждой из полос поглощения, а также излучение люминесценции осуществляются похожим образом в

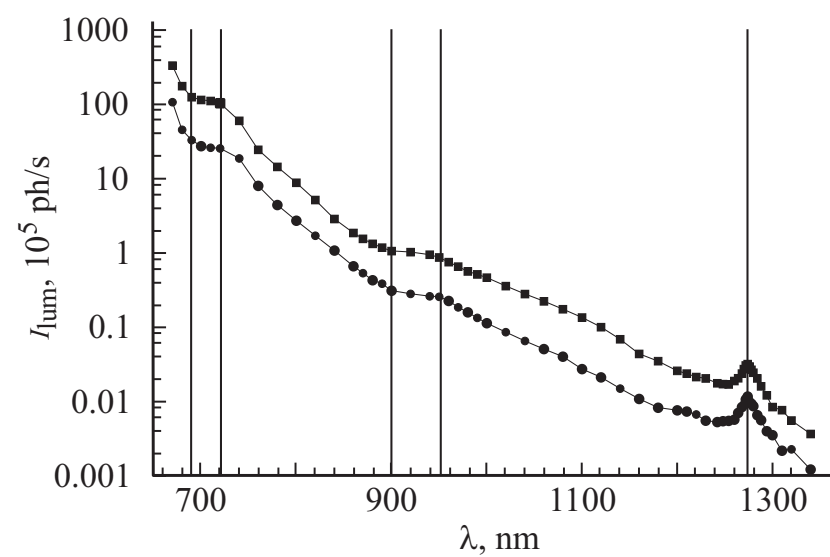

Рис. 2. Спектры люминесценции водного раствора ФС при возбуждении на длинах волн 405 (квадраты, [16]) и $660 \mathrm{~nm}$ (кружки). Вертикальными линиями показаны характерные особенности обоих спектров. 


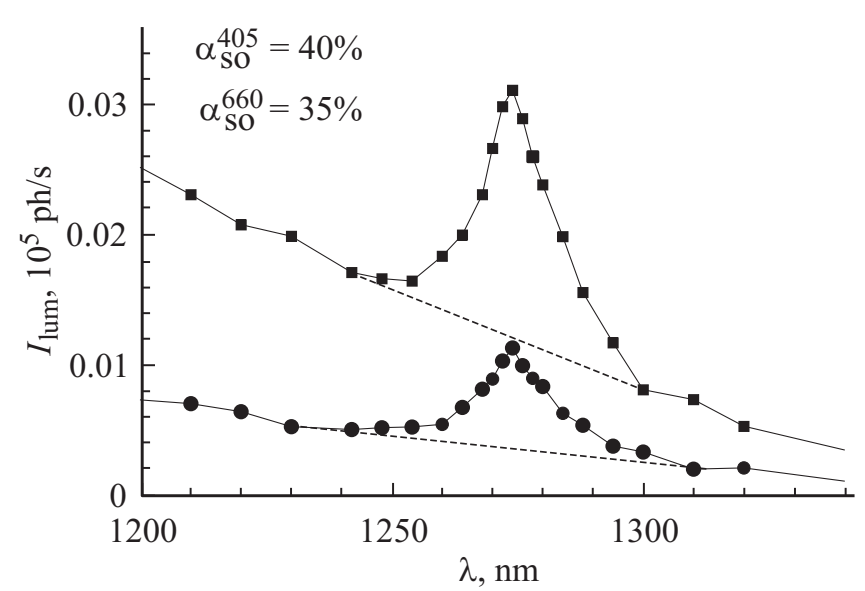

Рис. 3. Пик фосфоресценции СК при возбуждении на длинах волн 405 (квадраты, [16]) и $660 \mathrm{~nm}$ (кружки). Штриховая линия - уровень сигнала люминесценции ФС.

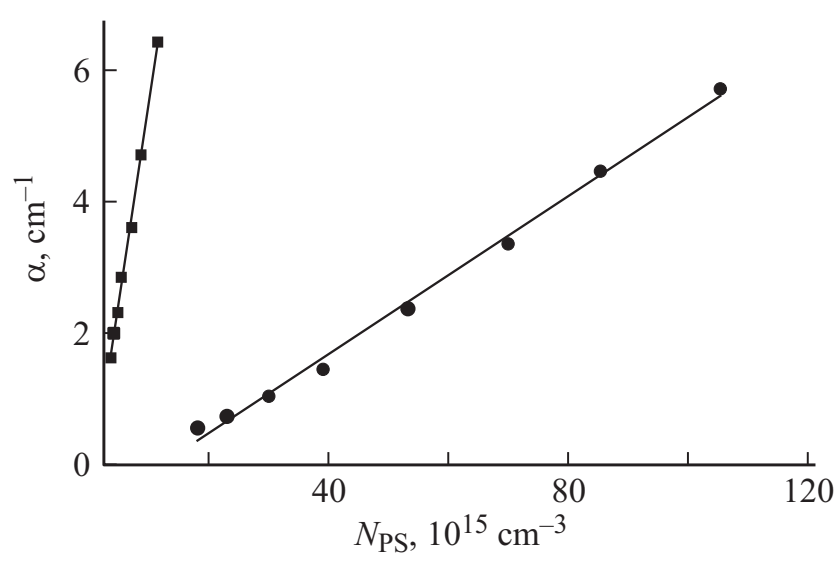

Рис. 4. Коэффициент поглощения водного раствора ФС Радахлорин в зависимости от концентрации $Ф С ~ N$ при возбуждении на длинах волн 405 (квадраты) и $660 \mathrm{~nm}$ (кружки).

рамках известной модели Яблонского [18]: непосредственно после поглощения фотона лазерного излучения происходит быстрая релаксация с возбужденного синглетного уровня энергии молекулы ФС на нижнее колебательное состояние первого триплетного уровня энергии, с последующим испусканием фотона люминесценции.

Кроме того, была исследована зависимость коэффициента поглощения раствора от концентрации ФС при возбуждении на длинах волн 405 и $660 \mathrm{~nm}$. При этом интенсивность лазерного пучка, прошедшего через кювету, с хорошей точностью следовала закону БугераЛамберта-Бера:

$$
I=I_{0} e^{-\alpha L},
$$

где $\alpha=N \sigma$ - коэффициент поглощения раствора, $N$ концентрация ФС в растворе, $\sigma$ - эффективное сечение поглощения, $L-$ длина пути лазерного излучения в растворе.
Полученные зависимости коэффициентов поглощения от концентрации ФС приведены на рис. 4, откуда были определены эффективные сечения поглощения, оказавшиеся равными $\sigma_{405}=(5.9 \pm 0.3) \cdot 10^{-17} \mathrm{~cm}^{3}$ и $\sigma_{660}=(5.9 \pm 0.3) \cdot 10^{-18} \mathrm{~cm}^{3}$.

На рис. 5 представлены зависимости сигнала фосфоресценции СК от концентрации Радахлорина. Видно, что при концентрации $6 \cdot 10^{16} \mathrm{~cm}^{-3}$ при возбуждении лазером $405 \mathrm{~nm}$ сигнал выходит на насыщение, в то время как при возбуждении лазером $660 \mathrm{~nm}$ насыщение не достигается даже при концентрации в два раза большей. Фитинг полученных зависимостей осуществлялся с помощью выражения

$$
I_{\mathrm{ph}}=C\left(1-e^{-\beta N}\right)
$$

где множитель в круглых скобках пропорционален поглощению лазерного излучения раствором ФС в пределах светящейся области, регистрируемой монохроматоpoм, $\beta=\sigma L_{\mathrm{eff}}, L_{\mathrm{eff}}-$ эффективная длина излучающей области, коэффициент $C=I_{0} \Phi \eta$, где $\Phi-$ квантовый выход СК, а $\eta-$ формфактор, определяемый долей полного излучения фосфоресценции, попадающей на щель монохроматора.

Хорошее согласие между экспериментальными данными на рис. 5 и результатом фитинга по формуле (2) позволяет сделать вывод о том, что коэффициент $C$ и, следовательно, квантовый выход образования СК не зависят от концентрации ФС. Этот вывод должен учитываться при создании моделей генерации СК. Полученные на основе фитинга данных эксперимента функцией (2) значения коэффициентов $\beta$ оказались следующими: $\beta_{405}=(6.2 \pm 0.6) \cdot 10^{-16} \mathrm{~cm}^{3}$ и $\beta_{660}=(6.9 \pm 1.0) \cdot 10^{-17} \mathrm{~cm}^{3}$. В условиях нашего эксперимента $L_{\text {eff }}=1 \mathrm{~mm}$, при этом оценки эффективных сечений поглощения $\sigma_{405}$ и $\sigma_{660}$, получаемых на основе этих значений $\beta$, хорошо согласуются с полученными на основе измерения коэффициента поглощения (рис. 4).

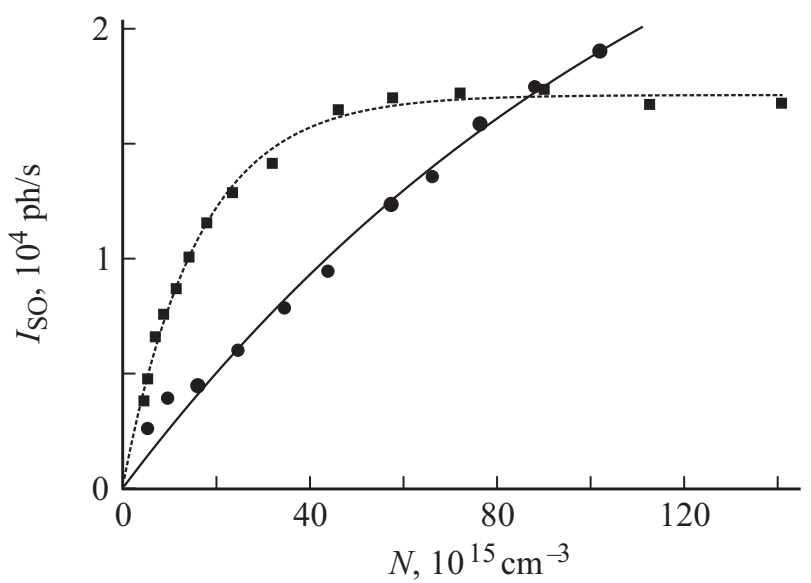

Рис. 5. Зависимость сигнала фосфоресценции СК на длине волны $1274 \mathrm{~nm}$ от концентрации ФС $N$ при возбуждении на длинах волн 405 (квадраты) и $660 \mathrm{~nm}$ (кружки). 


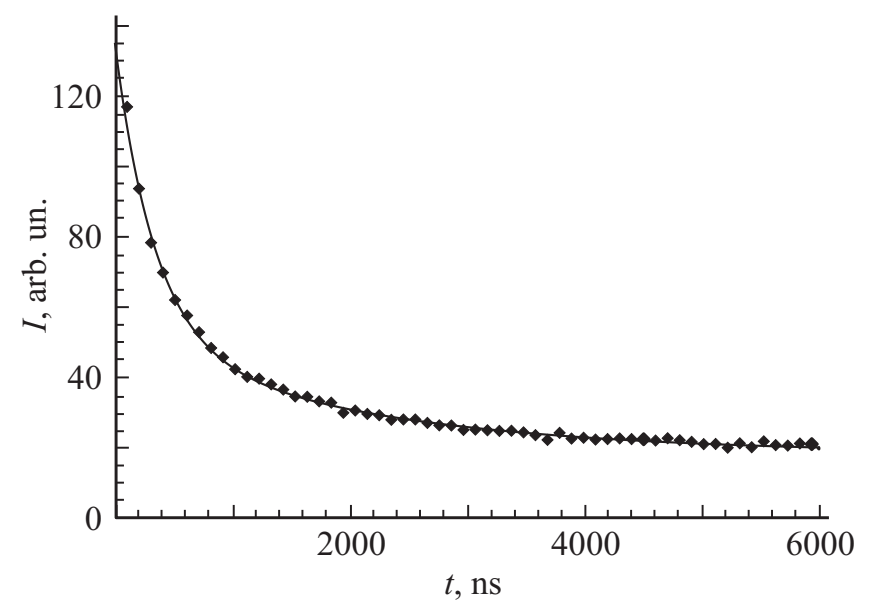

Рис. 6. Затухание сигнала люминесценции на длине волны $1080 \mathrm{~nm}:$ экспериментальные данные (ромбы) и их аппроксимация (сплошная кривая).

Определение времен жизни возбужденных триплетных состояний ФС осуществлялось с помощью исследования кинетики сигналов люминесценции на разных длинах волн с высоким временным разрешением при возбуждении импульсным излучением лазера на длине волны $660 \mathrm{~nm}$. На рис. 6 представлена характерная экспериментальная кривая затухания сигнала люминесценции на длине волны $1080 \mathrm{~nm}$. Подобные кривые затухания были получены и на других длинах волн люминесценции в диапазоне 940-1350 nm. Выяснилось, что полученные экспериментальные сигналы хорошо аппроксимируются двухэкспоненциальной функцией

$$
I=A_{1} e^{-t / \tau_{1}}+A_{2} e^{-t / \tau_{2}}+y_{0} .
$$

Для всех длин волн, кроме области в районе пика СК, характерные времена затухания оказались следующими: $\tau_{1}=0.32 \pm 0.03 \mu \mathrm{s}$ и $\tau_{2}=2.0 \pm 0.3 \mu \mathrm{s}$, что согласуется с временами, полученными при возбуждении в полосе $405 \mathrm{~nm}$ в работе [17]. Характеристическое время $\tau_{2}$ может быть ассоциировано с временем жизни первого триплетного состояния Радахлорина $[17,19]$, а время $\tau_{1}-\mathrm{c}$ релаксационными процессами, проходящими в многокомпонентной смеси этого ФС. На длинах волн в районе $1270 \mathrm{~nm}$ характерное время $\tau_{1}$ оставалось таким же, как и на других длинах волн, однако $\tau_{2}$ возрастало, и на длине волны $1274 \mathrm{~nm}$ достигало значения $4.0 \pm 0.5 \mu \mathrm{s}$, что может свидетельствовать о наличии СК в растворе.

\section{Выводы}

Таким образом, в настоящей работе получен и исследован спектр люминесценции водного раствора ФС Радахлорина при возбуждении лазерным излучением на длине волны $660 \mathrm{~nm}$. На фоне люминесценции ФС обнаружен пик фосфоресценции СК с максимумом на длине волны $1274 \mathrm{~nm}$, а также определен его вклад в общий сигнал. Проведено сравнение со спектром, полученным ранее при возбуждении на длине волны $405 \mathrm{~nm}$, и показано, что оба спектра имеют в целом одинаковый характер, что свидетельствует о единообразии происходящих в обоих случаях процессов релаксации. На основании зависимости коэффициента поглощения от концентрации ФС определены эффективные сечения поглощения для обеих длин волн возбуждения. Показано, что квантовый выход образования СК не зависит от концентрации ФС. Продемонстрировано, что затухание сигнала люминесценции носит двухэкспоненциальный характер, и определены характерные времена затухания. Полученные в работе результаты могут быть использованы для оптимизации методов генерации и детектирования СК в растворах и биологических объектах.

Работа выполнена при финансовой поддержке РНФ (проект № 14-13-00266). Авторы благодарны компании РадаФарма за предоставление образцов Радахлорина ${ }^{\circledR}$ для проведения экспериментов.

\section{Список литературы}

[1] Dougherty T.J., Gomer C.J., Henderson B.W., Jori G., Kessel D., Korbelik M., Moan J., Peng Q. // J. National Cancer Inst. 1998. V. 90. P. 889-905.

[2] Henderson B.W., Dougherty T.J. // Photochem. photobiol. 1992. V. 55. P. $145-157$.

[3] Dolmans D.E., Fukumura D., Jain R.K. // Nature rev. cancer. 2003. V. 3. P. $380-387$.

[4] De Rosa M.C., Crutchley R.J. // Coord. Chem. Rev. 2002. V. 233. P. 351-371.

[5] Douillard S., Olivier D., Patrice T. // Photochem. Photobiol. Sci. 2009. V. 8. N 3. P. $405-413$.

[6] Privalov V.A., Lappa A.V., Seliverstov O.V., Faizrakhmanov A.B., Yarovoy N.N., Kochneva E.V., Evnevich M.V., Anikina A.S., Reshetnicov A.V., Zalevsky I.D., Kemov Y.V. // Int. Symposium on Biomed. Optics. Int. Soc. Optics and Photonics. 2002. P. 178-189.

[7] Ji W., Yoo J.W., Bae E.K., Lee J.H., Choi C.M. // Photodiagnosis and photodynamic therapy. 2013. V. 10. P. $120-126$.

[8] Kochneva E.V., Filonenko E.V., Vakulovskaya E.G., Scherbakova E.G., Seliverstov O.V., Markichev N.A., Reshetnickov A.V. // Photodiagnosis and photodynamic therapy. 2010. V. 7. P. $258-267$.

[9] Vahabi S., Fekrazad R., Ayremlou S., Taheri S., Zangeneh $N$. // Journal of Dentistry, Tehran University of Medical. 2011. V. 8. P. 48-54.

[10] Belashov A.V., Zhikhoreva A.A., Belyaeva T.N., Kornilova E.S., Petrov N.V., Salova A.V., Semenova I.V., Vasyutinskii O.S. // Opt. Lett. 2016. V. 41. P. 5035-5038.

[11] Ferreira J., Menezes P.F., Kurachi C., Sibata C., Allison R.R., Bagnato V.S. // Laser Phys. Lett. 2007. V. 5. N 2. P. 156.

[12] Vargas F., Díaz Y., Yartsev V., Marcano A., Lappa A. // Ciencia. 2004. V. 12. P. 70-77. 
[13] Бельтюкова Д.М, Васютинский О.С., Глазов А.Л., Семенова И.В., Смолин А.Г. // Опт. и спектр. 2017. Т. 122. № 2. C. 252-257.

[14] Beltukova D.M., Semenova I.V., Smolin A.G., Vasyutinskii O.S. // Chem. Phys. Lett. 2016. V. 662. P. 127-131.

[15] Ильина А.Д., Глазов А.Л., Семенова И.В., Васютинский О.С. // Опт. и спектр. 2016. Т. 120. № 6. С. 935-940.

[16] Belik V.P., Gadzhiev I.M., Petrenko M.V., Petrov M.A., Semenova I.V., Vasyutinskii O.S. // Chem. Phys. Lett. 2016. V. 665. P. 127-130.

[17] Belik V.P., Gadzhiev I.M., Semenova I.V., Vasyutinskii O.S. // Spectrochim. Acta A. 2017. V. 178. P. 181-184.

[18] Wayne R.P. Principles and Applications of Photochemistry. Oxford Univ. Press, 1988. 268 р. Перевод: Уэйн Р. Основы и применение фотохимии. Мир, 1991. 304 с.

[19] Isakau H., Parkhats M., Knyukshto V., Dzhagarov B., Petrov E., Petrov P. // J. Photo chem. Photobiol. B. 2008. V. 92. P. $165-174$. 